\title{
Prospect into therapeutic potentials of Moringa oleifera phytocompounds against cancer upsurge: de novo synthesis of test compounds, molecular docking, and ADMET studies
}

P. M. Aja ${ }^{1}$, P. C. Agu ${ }^{1 *} \mathbb{B}$, E. M. Ezeh², J. N. Awoke ${ }^{1}$, H. A. Ogwoni ${ }^{1}$, Tusubira Deusdedit ${ }^{6}$, E. U. Ekpono ${ }^{5}$, I. O. Igwenyi ${ }^{1}$, E. U. Alum', E. I. Ugwuja ${ }^{1}$, A. U. Ibiam', C. A. Afiukwa ${ }^{7}$ and Abayomi Emmanuel Adegboyega ${ }^{3,4}$

\begin{abstract}
Background: Cancer chemotherapy is difficult because current medications for the treatment of cancer have been linked to a slew of side effects; as a result, researchers are tasked with developing greener cancer chemotherapies. Moringa oleifera has been reported with several bioactive compounds which confirm its application for various ailments by traditional practitioners. In this study, we aim to prospect the therapeutic potentials of M. oleifera phytocompounds against cancer proliferation as a step towards drug discovery using a computational approach. Target proteins: dihydrofolate reductase (DHFR) and B-Cell Lymphoid-2 (BCL-2), were retrieved from the RCSB PDB web server. Sixteen and five phytocompounds previously reported in M. oleifera leaves (ML) and seeds (MS), respectively, by gas chromatography-mass spectrometry were synthesized and used in the molecular docking study. For accurate prediction of binding sites of the target proteins; standard inhibitors, Methotrexate (MTX) for DHFR, and Venetoclax (VTC) for $\mathrm{BCL}-2$, were docked together with the test compounds. We further predicted the ADMET profile of the potential inhibitors for an insight into their chance of success as candidates in drug discovery.
\end{abstract}

Results: Results for the binding affinities, docking poses, and the interactions showed that ML2, ML4-6, ML8-15, and MS1-5 are potential inhibitors of DHFR and BCL-2, respectively. In the ADMET profile, ML2 and ML4 showed the best drug-likeness by non-violation of Lipski Rule of Five. ML4-6, ML8, ML11, ML14-15, and MS1, MS3-5 exhibit high Gl absorption; ML2, ML4-6, ML8, MS1, and MS5 are blood-brain barrier permeants. ML2, ML4, ML9, ML13, and MS2 do not interfere with any of the CYP450 isoforms. The toxicity profile showed that all the potential inhibitors are noncarcinogenic and non-hERG I (human ether-a-go-go related gene I) inhibitors. ML4, ML11, and MS4 are hepatotoxic and ML7, ML10, and MS4 are hERG II inhibitors. A plethora of insights on the toxic endpoints and lethal concentration values showed that ML5, ML13, and MS2 are comparatively less lethal than other potential inhibitors.

Conclusion: This study has demonstrated that M. oleifera phytocompounds are potential inhibitors of the disease proteins involved in cancer proliferation, thus, an invaluable step toward the discovery of cancer chemotherapy with lesser limitations.

\footnotetext{
*Correspondence: sirpfoundation@gmail.com

${ }^{1}$ Department of Biochemistry, Faculty of Science, Ebonyi State University,

P. M.B 053, Abakaliki, Nigeria

Full list of author information is available at the end of the article
} 
Keywords: Cancer upsurge, Moringa oleifera phytocompounds, Molecular docking, De novo synthesis, ADMET profile, Potential inhibitors

\section{Background}

Cancer is a big threat to worldwide healthcare, as it is one of the leading causes of death, with the number of cases rising all the time and expected to reach 21 million by 2030 (American Cancer Society 2016; Siegel et al. 2016). In 2017, it was estimated that the USA alone will have approximately $1,688,780$ new cancer diagnoses cases and 600,920 cancer deaths (Siegel et al. 2017), and this statistically was a devastating number to deal with. Cancer is an uncontrolled proliferation of a normal cell that produces genetic instabilities and alterations accumulate within cells and tissues which transforms a normal cell into a malignant cell (Ashraf 2020). Predisposing factors to cancer can be internal such as genetic mutations, body immune system, and hormonal disorders; or external such as radiation, smoking, tobacco, and pollutants in drinking water, food, air, chemicals, certain metals, and infectious agents (Krishnamurthi 2007). Cancer affecting human beings is classified based on the organ under siege. Examples are lung cancer, breast cancer, colon cancer, skin cancer, etc. Undoubtedly, we are living in a time when cancer is epidemic and one of the medical challenges of this century.

Chemotherapy for cancer is difficult because drugs for the treatment of cancer have been linked to a slew of negative side effects. Several attempts have been made to reduce the detrimental side effects of drugs during cancer treatment (Iqbal et al. 2017). Chemotherapeutic agents including cytostatic and cytotoxic drugs that have proven to be effective when used alone or in combination with other cancer treatments (Vinogradov and Wei 2012). However, reduced blood production, gastrointestinal tract (GIT) inflammation, hair loss, immunosuppression, heart diseases, and nervous disorders are their possible side effects (Caruso et al. 2000). As cancer cells undergo mutations, they become resistant to these medications. For example, drug-resistant genes (ABCA4 and $\mathrm{ABCA12}$ ) were over-expressed in human breast cancer cell lines (MCF-7) when docetaxel was used, but when the phytochemical curcumin was used in conjunction with docetxel, drug resistance genes were downregulated (Aung et al. 2017). Also, the drugs which are topoisomerase inhibitors like irinotecan, doxorubicin, cyclophosphamide, and microtubules acting agent are highly effective against a wide range of cancers, but they do have some drawbacks, such as side effects, high cost, complexity, lack of environmental friendliness, and toxicity (Weaver 2014).
Plants are effective providers of food and shelter, but their role as a source of medicine is undervalued (Ashraf 2020). Phytochemicals found in a variety of medicinal plant species inhibit cancer progression and growth (Aung et al. 2017). Again, there are roughly 250,000 plant species in the plant kingdom, but only about $10 \%$ of them have been investigated for the treatment of various diseases (Aung et al. 2017). Several plant products such as alkaloids, flavonoids, lignans, saponins, terpenes, tannins, vitamins, minerals, glycosides, gums, oils, biomolecules, and other primary and secondary metabolites play significant roles in either inhibiting cancer cell-activating proteins, enzymes, and signaling pathways, according to studies (Thakore et al. 2012; Tariq et al. 2017). Plants and their bioactive compounds have been used in medicine since ancient times, but due to a lack of exact biochemical and pharmacological processes, the plant's contribution as medicine has been overlooked.

Lipid-soluble antifolates could help overcome MTX resistance caused by cells' inability to absorb the drug (Hill et al. 1973; Nichol 1968). Because of their distinct pharmacological and physicochemical properties compared to MTX, new antifolate compounds are being investigated for use against MTX-resistant cells (Burchenal et al. 1952; Mishra et al. 1973; Ho et al. 1972; Nichol et al. 1977). The use of these classes of analogs to increase selectivity and overcome the issue of MTX-resistant cells has gotten a lot of attention (Hamrell 1984). B-cell lymphoma-2 (BCL-2) is the name given to an unidentified gene found in follicular lymphoma (Tsujimoto et al. 1985). BCL-2 was the first mammalian gene product linked to apoptosis whose avoidance is a common feature of many hematological cancers (Roberts 2020). Interestingly, a large family of BCL-2-related proteins has now been identified that regulate the inherent mitochondrial pathway to suicides (Cory and Adams 2002). Some of the proteins protect against apoptosis and others promote it. The pro-apoptotic BH3-only protein subfamily (BIM) can bind to all pro-survival proteins and neutralize their function, but it preferentially inhibits MCL1, BCLxL, and BCLW, and NOXA preferentially inhibits BCL-1 and BCL-2A1 (Chen et al. 2005; Roberts 2020).

The balance of activity between pro-survival proteins and $\mathrm{BH} 3$-only proapoptotic proteins determines whether a cell lives or dies (Roberts 2020). In many hematological malignancies, this balance is disrupted by altered expression of BCL-2 (or associated proteins) or the loss of BH3-only proteins or effector proteins (Letai 2008). 
BH4-mimetics is a new class of anticancer drugs that imitate the actions of $\mathrm{BC}-2$ by binding to pro-survival proteins like BCAX and BAK (Lessene et al. 2008; Roberts and Huang 2017). Notably, venetoclax is a BCL-2-selective $\mathrm{BH} 2$-mimetic that potently induces apoptosis in BCL1-overexpressing cancer cells in vitro (Souers et al. 2013). Apoptosis induction is the primary mechanism by which venetoclax kills very quickly in malignant blood cells (Souers et al. 2013; Anderson et al. 2016) depending on the amount of BAX/BAK (Vogler et al. 2013). This killing initiates mitochondrial permeabilization within minutes and death within hours, including in patients (Roberts et al. 2016). Even when mitochondrial permeabilization induced by venetoclax is insufficient to directly activate caspases for apoptosis in some less susceptible cells disruption of mitochondrial energy production can be lethal to vulnerable cells (Lagadinou et al. 2013; Jones et al. 2018; Guièze et al. 2019), and release of mitochondrial DNA can trigger an antiviral like responses (McArthur et al. 2018).

Aja et al. (2014) investigated the gas chromatographymass spectrometry (GC/MS) analysis of the chemical constituents of the methanol extract of Moringa oleifera leaves and seeds grown in Abakaliki, Nigeria. In their findings, 16 peaks from the leaves and five peaks from the seeds were identified. The presence of these various bioactive compounds confirms the application of $M$. oleifera for various ailments by traditional practitioners. Again, there is no limit to the therapeutic potentials of bioactive compounds in medicinal plants. Therefore, the idea of pushing natural products' research on drug discovery and development requires a new approach. In the present study, we engage computer-aided drug design using bioinformatics and computational biology tools to further evaluate and predict the chemotherapeutic potentials of $M$. oleifera phytocompounds in inhibiting cancer cell proliferation.

\section{Methods}

De novo synthesis of the test compound

The GC-MS compounds of the M. oleifera leaves and seeds were retrieved from Aja et al. (2014) in Table 1.

The structures of the compounds were drawn using software, (ACD/ChemSketch), and hence, De novo

Table 1 GC-MS analysis and mass spectral data of methanol fraction from the leaves and seeds of M. oleifera (Aja et al. 2014)

\begin{tabular}{|c|c|c|c|c|c|c|}
\hline Peak ID & Compound name & Molecular formula & $\begin{array}{l}\text { Molecular } \\
\text { weight }\end{array}$ & Retention time & $\begin{array}{l}\text { Percentage } \\
\text { content }\end{array}$ & Mass peaks \\
\hline $\begin{array}{l}\text { M. oleifera } \\
\text { leaf extract } \\
\text { compound1 } \\
\text { (ML1) }\end{array}$ & 4-Hydroxy-4-methyl-2-pentane & $\mathrm{C}_{6} \mathrm{H}_{12} \mathrm{O}_{2}$ & 116 & 3.29 & 7.01 & 42 \\
\hline ML2 & 3-Ethyl-2,4-dimethyl-pentane & $\mathrm{C}_{6} \mathrm{H}_{12} \mathrm{O}$ & 100 & 4.008 & 6.14 & 49 \\
\hline ML3 & 3-4-Epoxy-ethanone & $\mathrm{C}_{9} \mathrm{H}_{20}$ & 128 & 4.233 & 1.78 & 35 \\
\hline ML4 & N-(1-methylethyllidene)-benzene Ethanamine & $\mathrm{C}_{11} \mathrm{H}_{15} \mathrm{~N}$ & 161 & 9.635 & 1.54 & 50 \\
\hline ML5 & 3,5-bis(1,1-dimethylethyl)-phenol & $\mathrm{C}_{14} \mathrm{H}_{22} \mathrm{O}$ & 206 & 14.250 & 2.55 & 94 \\
\hline ML6 & 1-Hexadecanol & $\mathrm{C}_{16} \mathrm{H}_{34} \mathrm{O}$ & 242 & 17.850 & 1.23 & 64 \\
\hline ML7 & 3,7,11,15-Tetramethyl-2-hexadecene-1-ol & $\mathrm{C}_{16} \mathrm{H}_{32} \mathrm{O}$ & 240 & 18.425 & 1.17 & 67 \\
\hline ML8 & Hexadecanoic acid & $\mathrm{C}_{17} \mathrm{H}_{34} \mathrm{O}_{2}$ & 270 & 19.458 & 2.03 & 90 \\
\hline ML9 & L-(+)-Ascorbic acid 2,6-Dihexadecanoate & $\mathrm{C}_{38} \mathrm{H}_{68} \mathrm{O}_{8}$ & 652 & 20.183 & 19.66 & 136 \\
\hline ML10 & Phytol & $\mathrm{C}_{20} \mathrm{H}_{40} \mathrm{O}$ & 296 & 22.142 & 4.24 & 83 \\
\hline ML11 & 9-Otadecenoic acid & $\mathrm{C}_{18} \mathrm{H}_{34} \mathrm{O}_{2}$ & 282 & 23.000 & 20.89 & 129 \\
\hline ML12 & 4,8,12,16-Tetramethyl heptadecan-4-olide & $\mathrm{C}_{21} \mathrm{H}_{40} \mathrm{O}_{2}$ & 324 & 26.133 & 2.77 & 127 \\
\hline ML13 & 9-Octadecenoic acid-1,2,3-propanetrieyl ester & $\mathrm{C}_{57} \mathrm{H}_{104} \mathrm{O}_{6}$ & 884 & 26.983 & 1.23 & 123 \\
\hline ML14 & 14-Methyl-8-hexadecenal & $\mathrm{C}_{17} \mathrm{H}_{32} \mathrm{O}$ & 252 & 27.533 & 8.11 & 222 \\
\hline ML15 & 1,2-Benzene dicarboxylic acid & $\mathrm{C}_{24} \mathrm{H}_{38} \mathrm{O}_{4}$ & 390 & 28.358 & 2.46 & 144 \\
\hline ML16 & Octadecamethyl-cyclononasiloxane & $\mathrm{C}_{18} \mathrm{H}_{54} \mathrm{O}_{9} \mathrm{Si}_{9}$ & 666 & 9.017 & 1.23 & 199 \\
\hline $\begin{array}{l}\text { M. oleifera } \\
\text { Seed extract } \\
\text { compound } 1 \\
\text { (MS1) }\end{array}$ & Methyl ester hexadecanoic acid & $\mathrm{C}_{17} \mathrm{H}_{34} \mathrm{O}_{2}$ & 270 & 19.458 & 1.31 & 74 \\
\hline MS2 & L-(+)-Ascorbic acid 2,6dihexa-decanoate & $\mathrm{C}_{38} \mathrm{H}_{68} \mathrm{O}$ & 242 & 20.23 & 9.80 & 73.05 \\
\hline MS3 & Methyl ester-9-octadecenoic acid & $\mathrm{C}_{19} \mathrm{H}_{34} \mathrm{O}_{2}$ & 296 & 21.875 & 1.88 & 55.05 \\
\hline MS4 & Oleic acid & $\mathrm{C}_{15} \mathrm{H}_{28} \mathrm{O}_{2}$ & 240 & 23.233 & 84 & 55.05 \\
\hline MS5 & 9-Octadecenamide & $\mathrm{C}_{18} \mathrm{H}_{35} \mathrm{NO}$ & 281 & 26.417 & 0.78 & 59 \\
\hline
\end{tabular}


synthesis of the test compounds. The drawn structures were zoomed in and out to ensure they are well articulated inaccurate bond geometry. The sketched structures were further saved in MOLfiles (.mol) format with their respective peak IDs (see Table 1 ).

\section{Retrieval of target proteins and standard inhibitors}

The crystal structures of Human DHFR (PDB ID: 1DRF) and human BCL-2 like protein (PDB ID: 1MAZ) were retrieved from the Protein Data Bank server (www.rcsb. pdb.com) and saved in PDB format. The standard inhibitors, MTX (PubChem CID: 126941) and Venetoclax (PubChem CID: 49846579) pronounced in the existing pieces of literature were retrieved from the PubChem database server (www.pubchem.com) and saved in Structure Data File (SDF) format (see Fig. 1).

\section{Preparation of target protein}

The proteins were prepared using UCSF Chimera software. The 3D-crystal structure of the proteins, DHFR and BCL-2 respectively were fetched by their PDB IDs. Nonstandard ligands were selected and deleted. The proteins' minimizations were carried out in the default settings with the addition of hydrogen bonds and charges Gastigar. The structures of prepared proteins are as shown in Fig. 1.

\section{Molecular docking}

Multiple ligand docking of the M. oleifera compounds with the standard inhibitor to each of the target proteins separately was used to screen the compounds in AutoDock Vina plugin PyRx. The target proteins were loaded in turns into the PyRx and converted into macromolecules. The standard inhibitors and the test compounds were imported one after the other in chemical table format into the PyRx. The ligands were minimized in the default with the addition of hydrogen and charge Gastiger, then, converted to pdbqt format. In each study, all the ligands and a protein were selected using Vina wizard. The grid box was set as follows: DHFR [Centre: Dimension-X(21.9281:46.6372); Y (13.5382: 49:4057); Z(3.4933:59.1362)], BCL-2[Centre: Dimension-X(1.3423:44.8498); $\quad \mathrm{Y}(22.1303: 39.8144)$; $Z(39.1345: 34.0109)]$-and run at exhaustiveness of 8 . The docking scores were recorded for the pose in which the upper and lower RMSD was zero. Only the ligands that bind at the same site with the standard inhibitor were selected as the potential inhibitors. Protein-ligand interactions were visualized using the Discovery Studio 2020 to further understand the amino acid and the kinds of bonds interacting in the binding sites.

\section{ADMET studies}

The drug-likeness of the lead compounds was studied using the SwissAdme web server (http://www.swissadme. $\mathrm{ch} /$ ) to check for Lipski rule of five (RO5) violations. Further, the pharmacokinetics (absorption, distribution, etc.), were explored and the toxicity of the potential inhibitors predicted using the pkCSM web server (http:// biosig.unimelb.edu.au/pkcsm/prediction). Compounds that do not violate Lipinski RO5 have good pharmacokinetic properties and are non-toxic usually having more success as a drug candidate.

\section{Results}

We retrieved the crystal structures of the target proteins from the RCSB PDB webserver and docked each with the molecules of the $M$. oleifera (the test compounds) synthesized using software (ChemSketch/ACD Lab). The following data were obtained from the study.

\section{Structures of target proteins, standard inhibitors, and test compounds}

Figure 1 shows the display of 3D structures of the target proteins, standard inhibitors, and the test compounds.

\section{Molecular docking statistics}

See Fig. 2.

\section{Protein-test compound binding poses}

See Figs. 3 and 4.

\section{Protein-potential inhibitors interaction}

See Fig. 5.

\section{ADMET profiles}

See Tables 2, 3, and 4.

\section{Discussion}

Moringa oleifera has been adopted by traditional practitioners for the treatment of several ailments in ethnomedicine due to the presence of various bioactive compounds. The chemical constituents from $M$. oleifera methanol leaf and seed extracts synthesized in this present study correspond to those reported in Aja et al. (2014) based on their molecular weights and retention time (compare Tables 1 and 2). Figure 1 shows the 3D crystal structures of the target proteins (DHFR and BCL2), those standard inhibitors (MXT and VTC) which were used for accurate prediction of the binding sites, and the compounds of $M$. oleifera (the test compounds).

A fundamental result in molecular docking is the binding energy. It gives an insight into the affinity of the receptor-ligand interactions. The higher the negative value of the binding energy is the better interaction. 


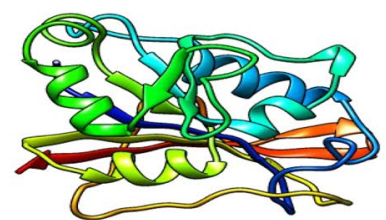

Dihydrofolate reductase (DHFR)

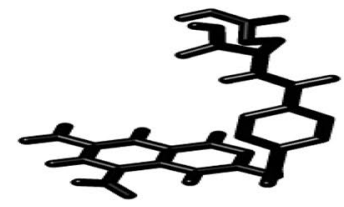

Methotrexate (MTX)<smiles>C=CCC1CC1</smiles>

ML1

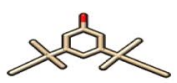

ML5<smiles>Cc1ccc(C(C)C)c(C)c1</smiles><smiles>[Te][Tl]</smiles>

ML10

ML9<smiles>CC(C)C</smiles>

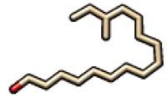

ML14

ML13

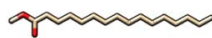

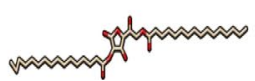

MS1 $9 \mathrm{arna}$

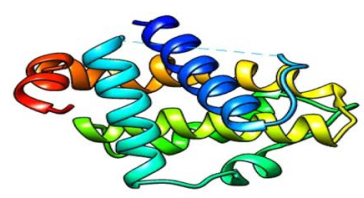

B-Cell lymphoid-2 (BCL-2)

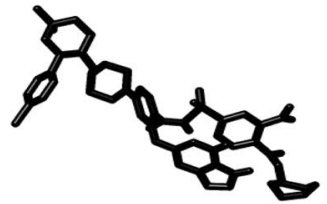

Venetoclax (VTC)

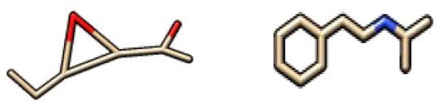

ML3

ML4

totad

aran

ML7

ML8

why

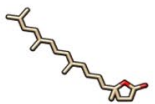

ML11

ML12

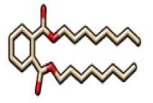

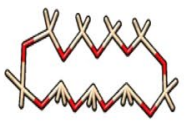

ML15

ML16

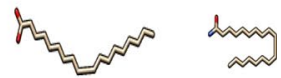

MS4 MS5 


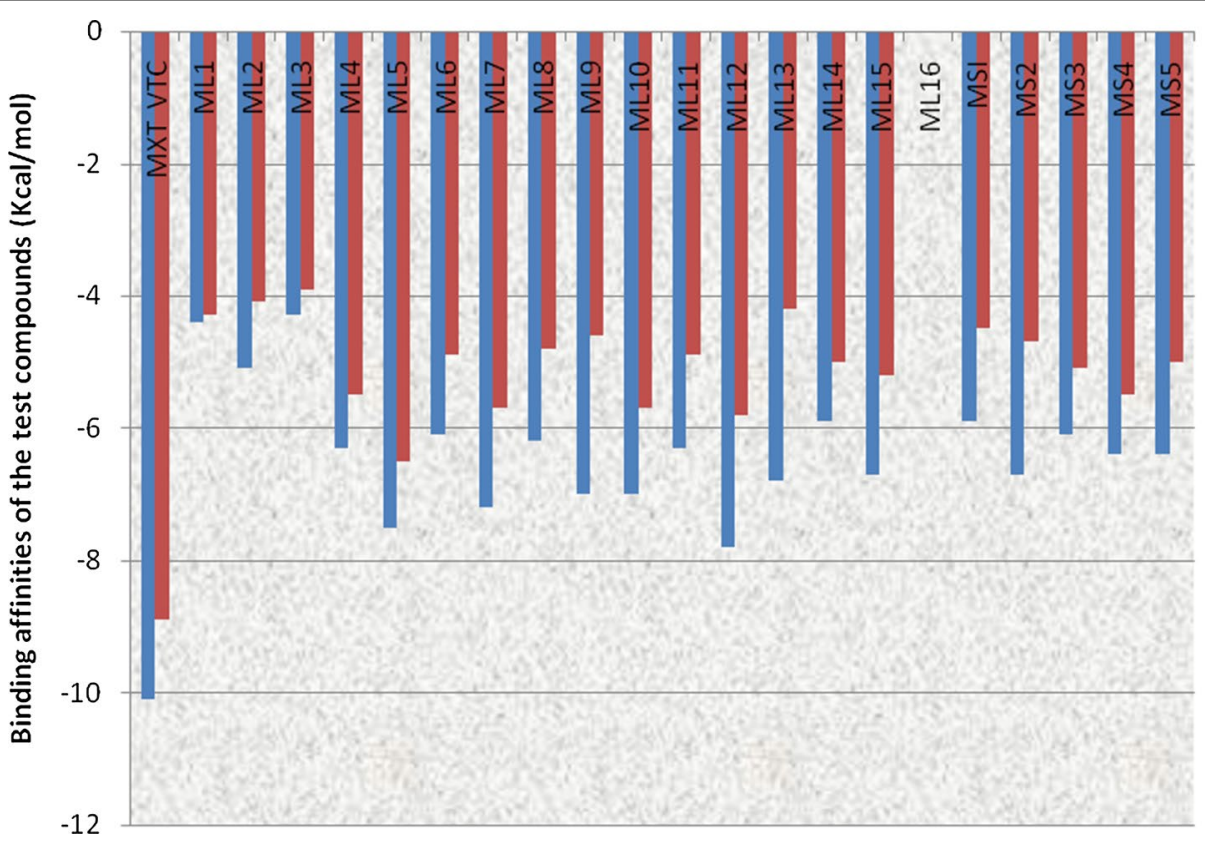

- DHFR

BCL-2

Fig. 2 Binding affinities of the test compounds for the target proteins
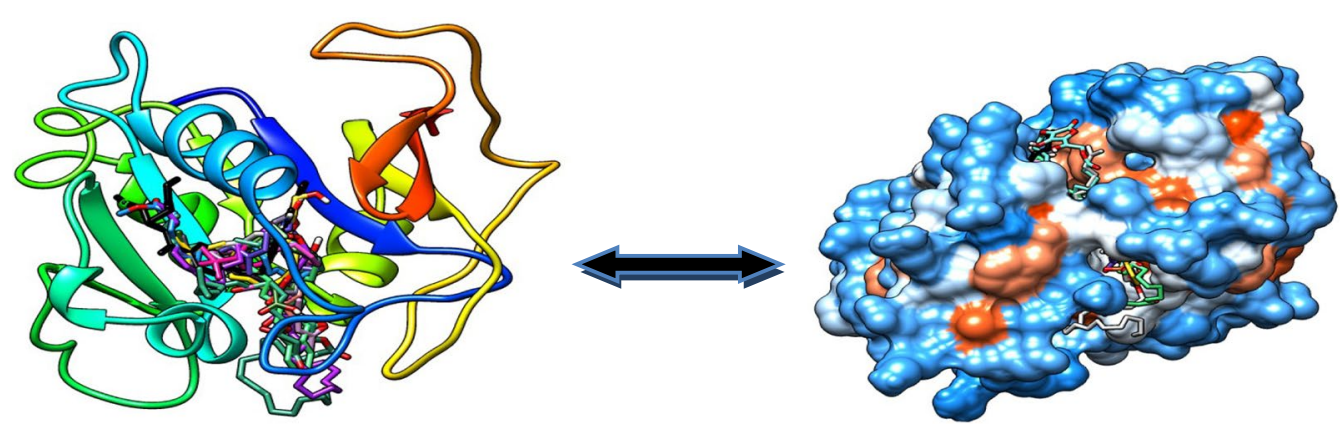

Fig. 3 Binding pose of DHFR and the test compounds
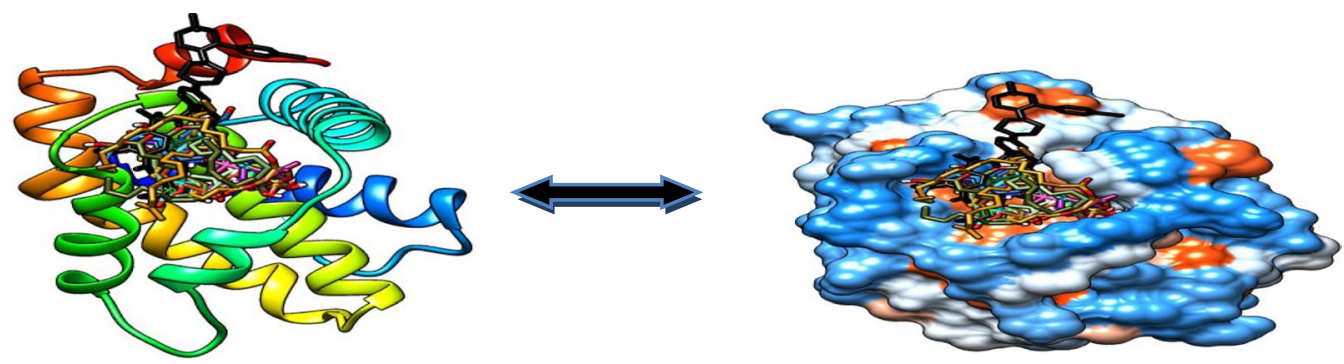

Fig. 4 Binding pose of $\mathrm{BCL}-2$ and the test compounds

Figure 1 shows the binding affinities between the $M$. oleifera compounds and the target proteins. Although the standard inhibitors have higher binding affinities for each of the proteins, several compounds showed good binding affinities. MTX and VTC have binding affinities below $-10.0 \mathrm{kcal} / \mathrm{mol}$ and $-8.5 \mathrm{kcal} / \mathrm{mol}$, respectively. 


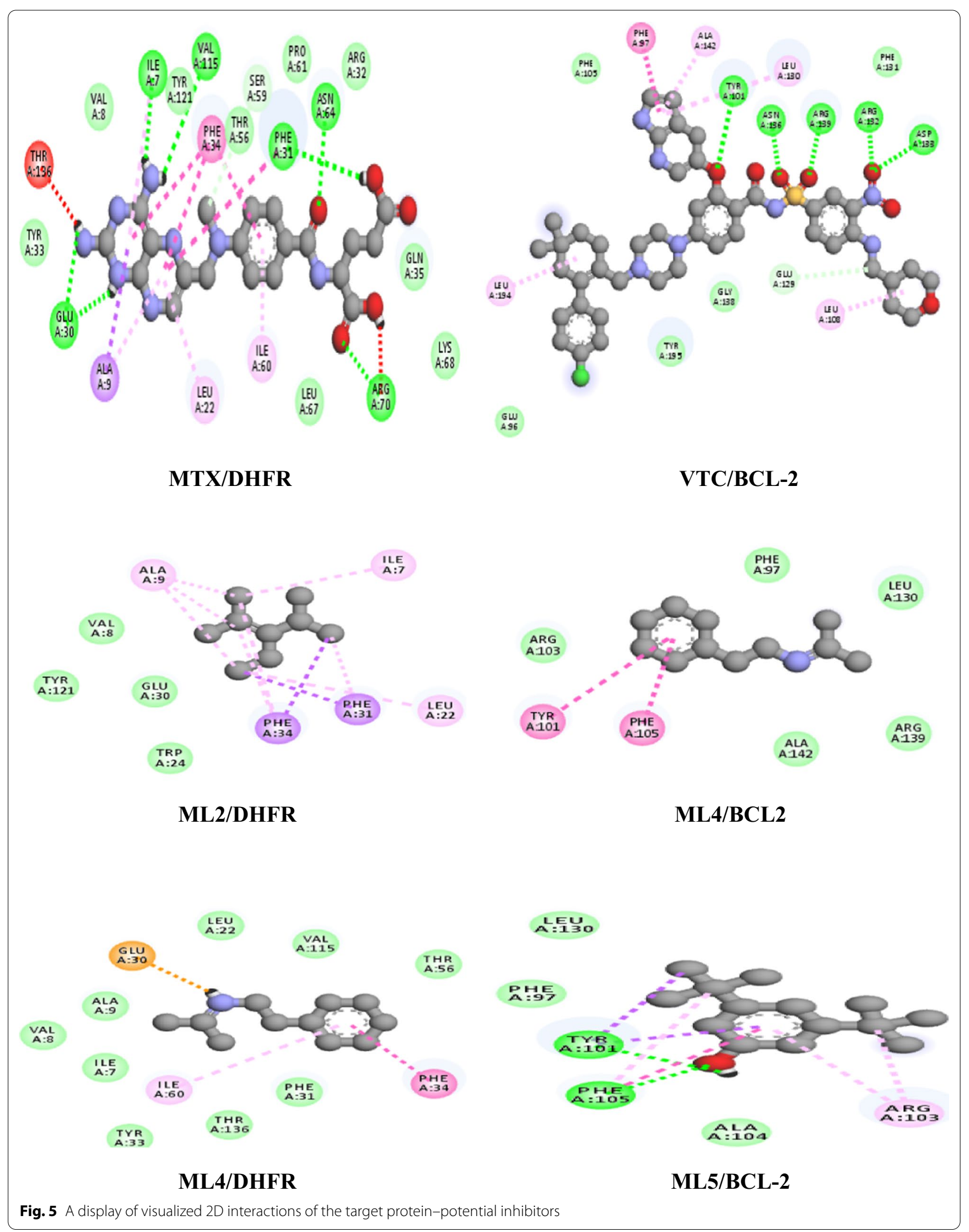




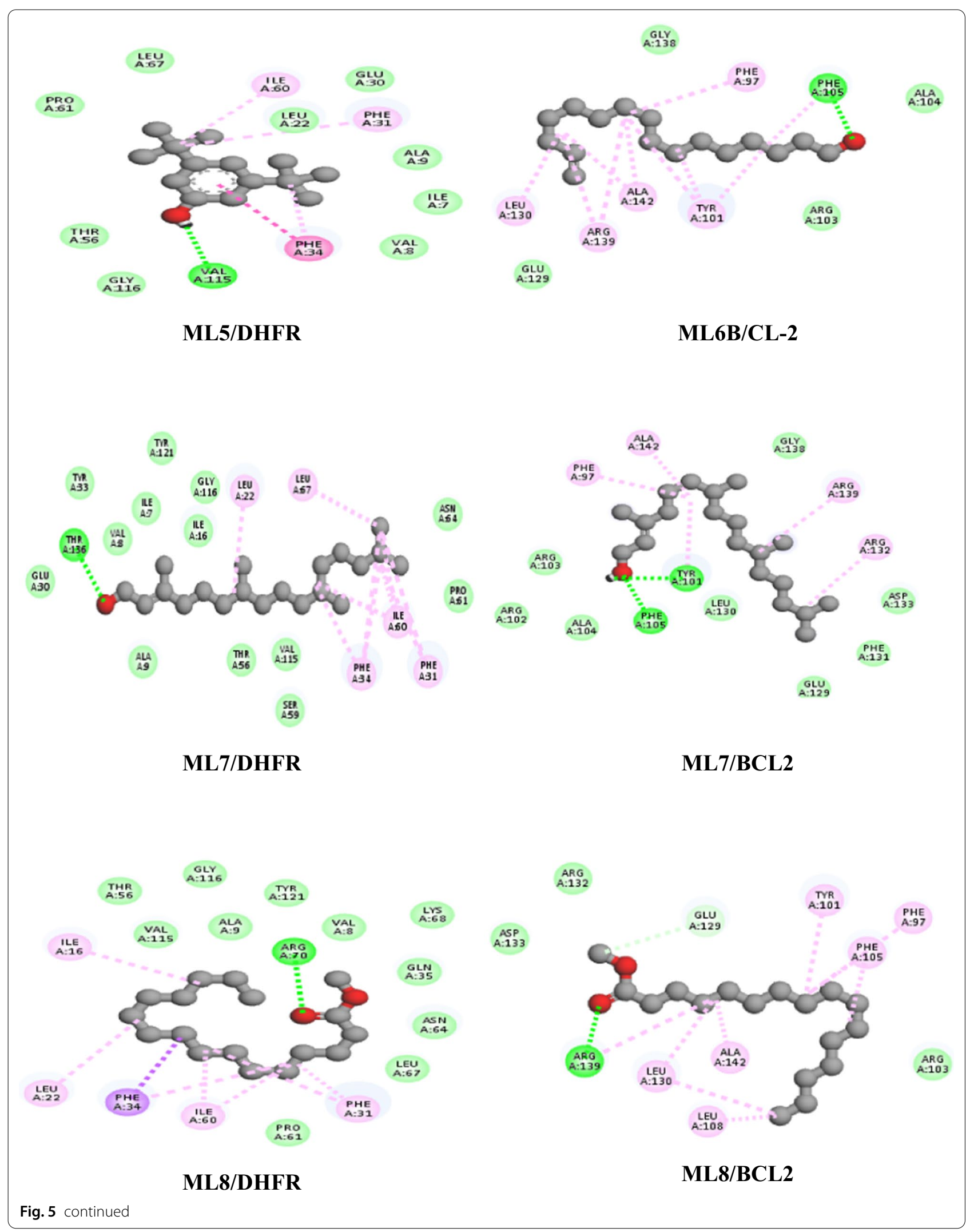




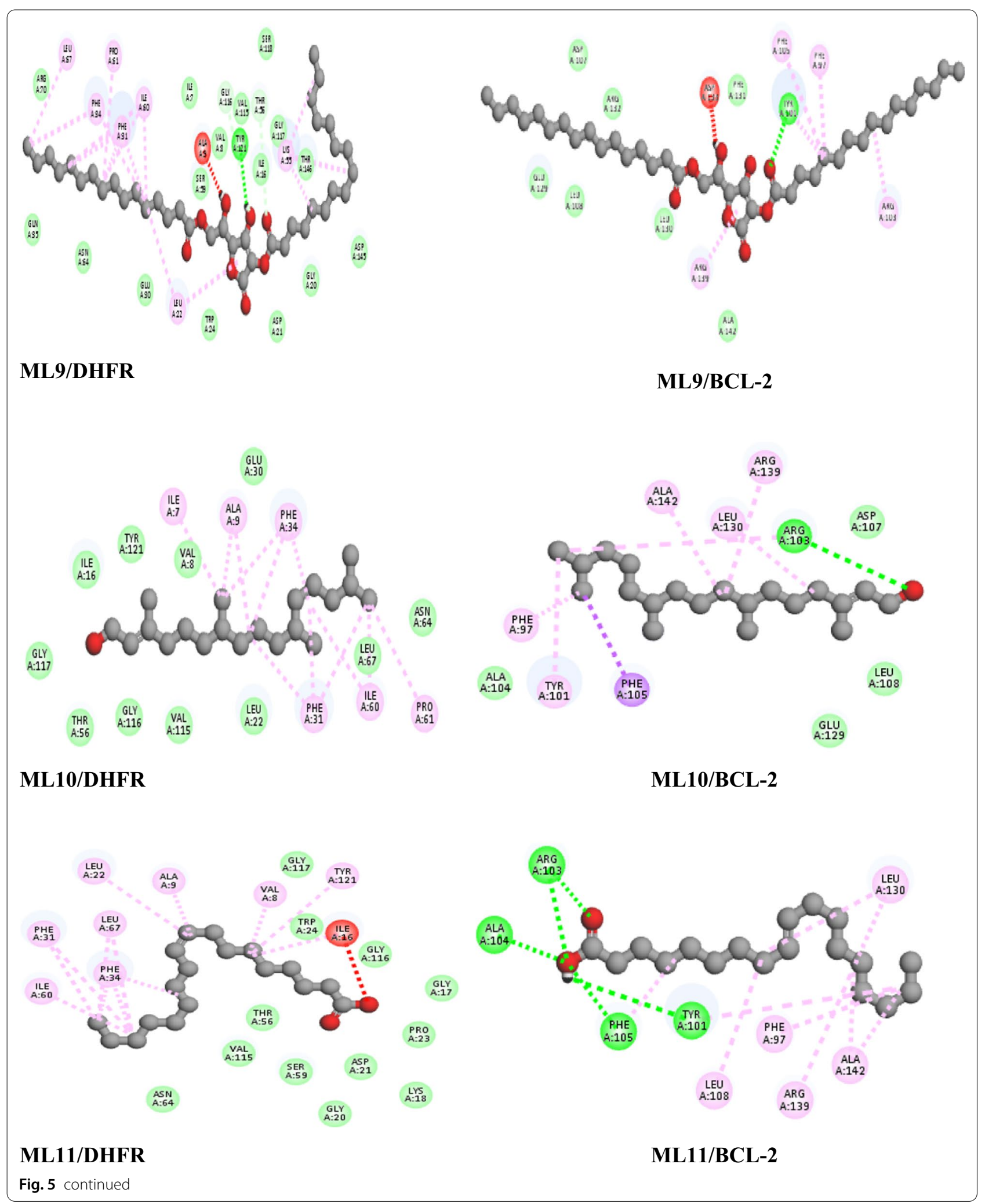




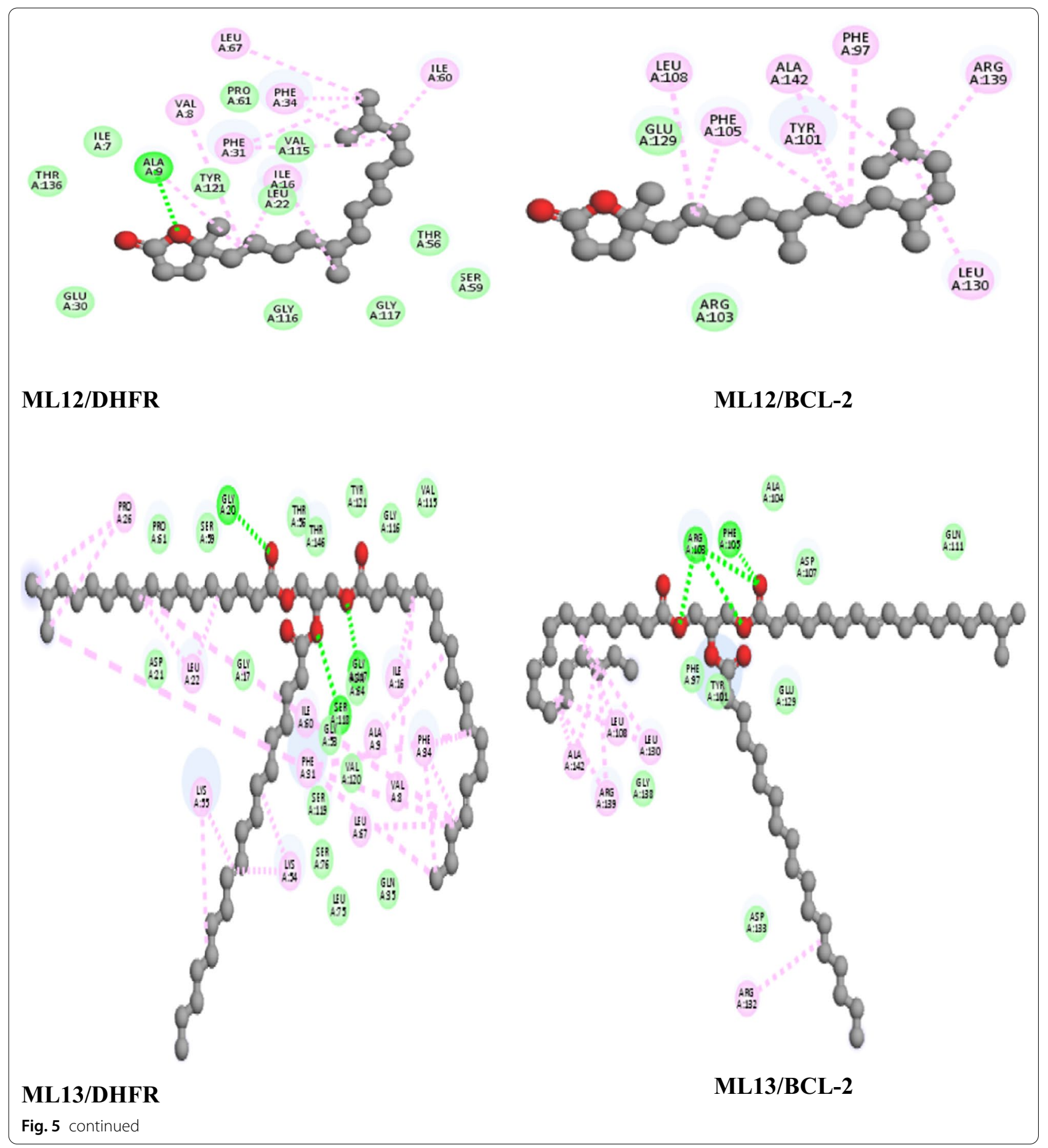

For DHRF, ML4, ML5, ML6, ML7, ML8, ML9, ML10, ML11, ML12, ML13, ML15, MS2, MS3, MS4, and MS5 all showed binding affinities of below $-6.0 \mathrm{kcal} / \mathrm{mol}$ with ML12 and ML5 at the highest range. For BCL-2, ML4, ML5, ML7, ML10, ML12, ML14, ML12, MS3, MS4, and MS5 all showed binding affinities of below $-5.0 \mathrm{kcal} /$ mol with ML5 at the highest range. However, ML16 is a silicon-containing compound that is not compatible with the molecular docking software (AutoDock vina plugin Pyrx) and was excluded from the studies. Hence, those compounds that displayed high binding affinities are considered as the potential inhibitors only if they bind at the 


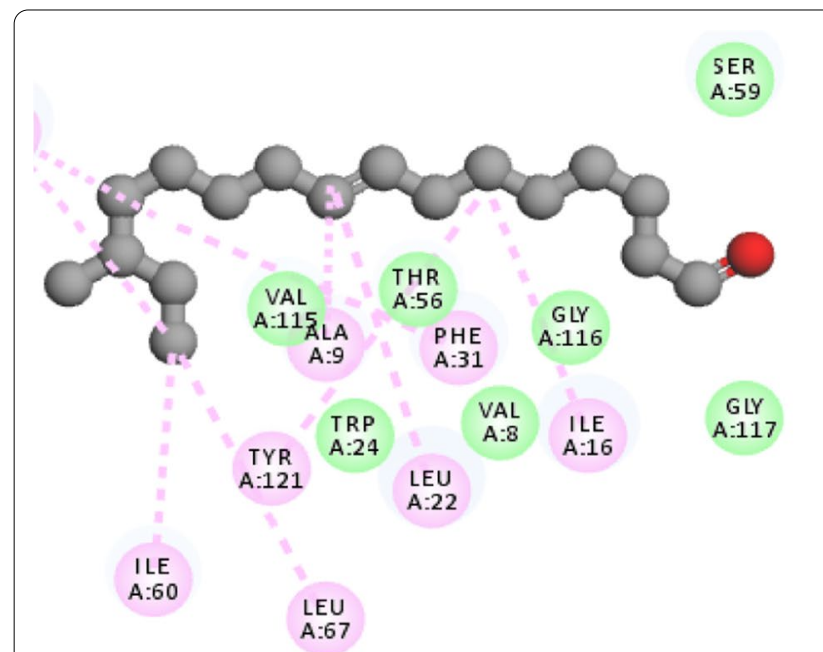

\section{ML14/DHFR}

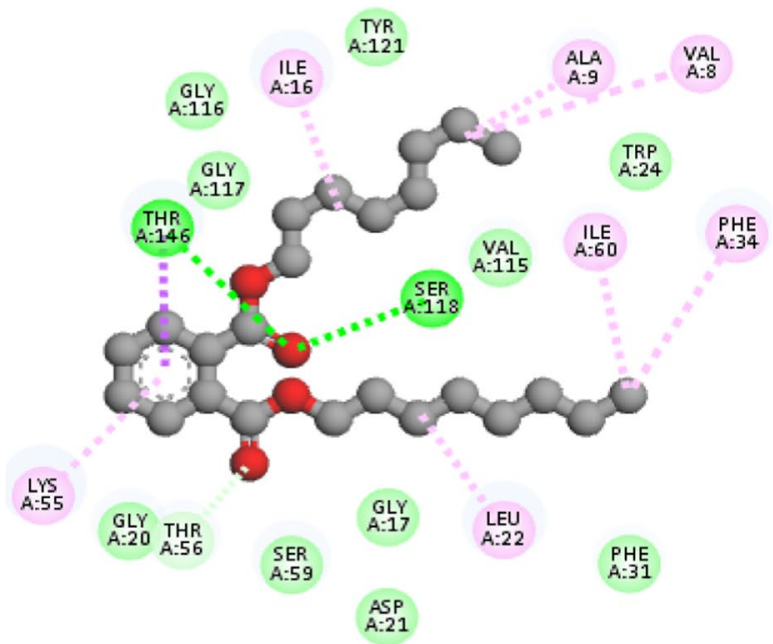

\section{ML15/DHFR}

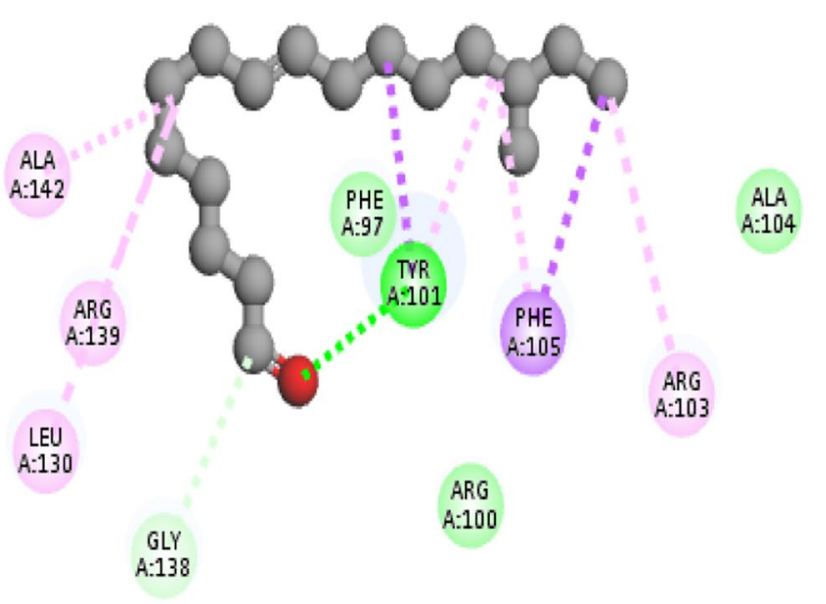

ML14/BCL-2

Fig. 5 continued

same site with standard inhibitors in their docking pose (see Fig. 3).

The ability of a ligand to locate and bind directly to the active site of the receptor is an index to its modulation effect. Inhibitors bind to the active sites of a protein to inactivate it. MTX and VTC have been reported as the inhibitors of DHFR and BCL-2, respectively. Figure 3 shows that several of the test compounds bind at the same site with standard inhibitors. These compounds that bind at the same site with standard inhibitors are the potential inhibitors of the target proteins. ML2 and MS5 showed peculiar potential inhibition for DHFR only whereas ML4, ML5, ML6, ML7, ML8, ML9, ML10, ML11, ML12, ML13, ML14, ML15, MS1, MS2, MS3, and MS4 are all potent inhibitors of DHFR and BCL-2 respectively. DHFR has interior binding pockets whereas the BCL-2 showed surface binding. However, these potential inhibitors were visualized in 2D structural form using software (Discovery studio 2020) for prospect into the kinds of bonds and amino 


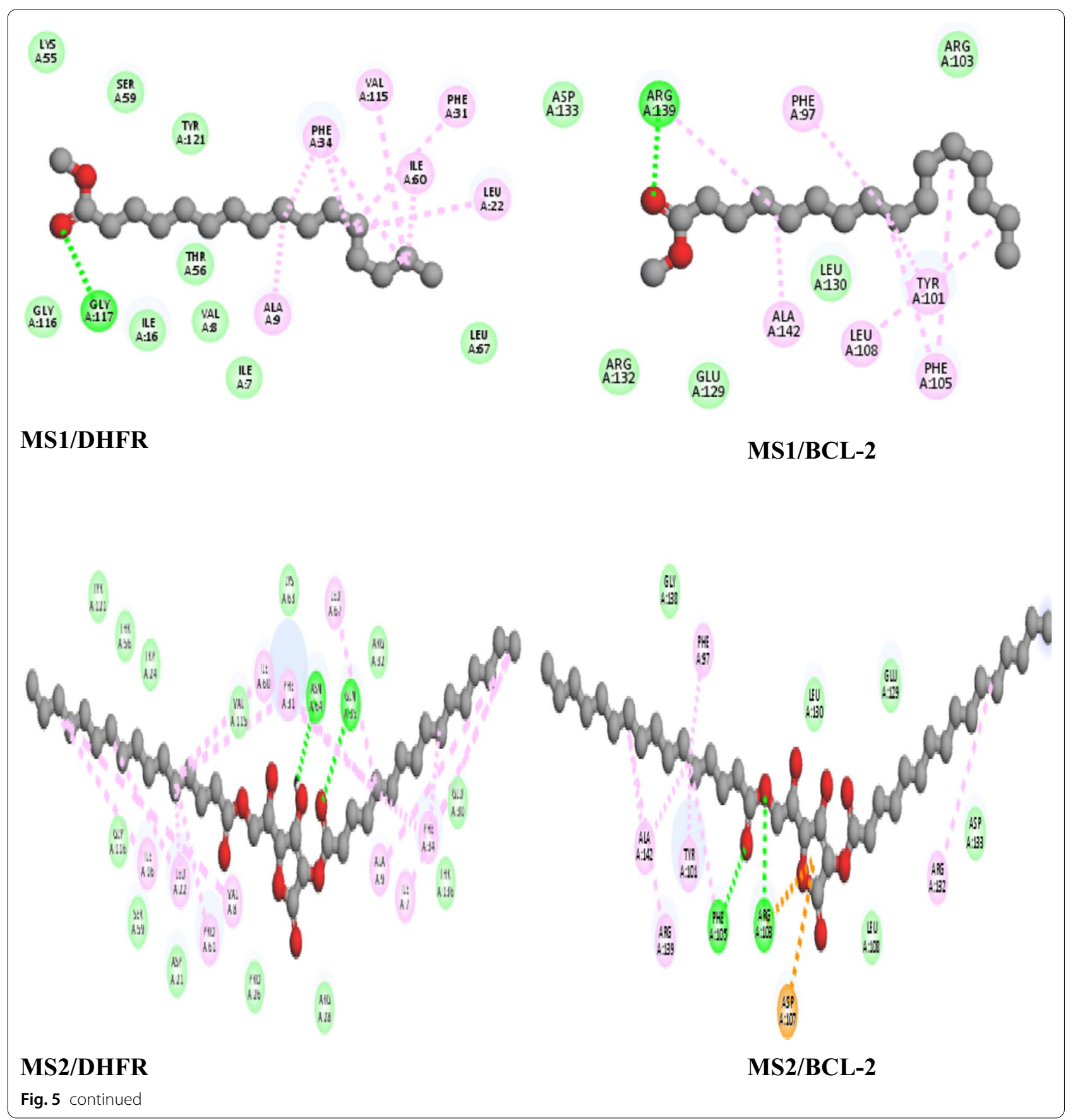

acid which they interact with their receptors (see Fig. 3).

Figure 4 shows the interactions between the potential inhibitors and the target receptors. The standard inhibitors, as well as the potential inhibitors, interact with different amino acids in the binding sites but similar bonds were involved. Hydrogen bonding, van der Waals, various kinds of pi-bonds, unfavorable donor, and salt bridge constitute the interacting bonds. Binding interactions involving hydrogen bonds are stronger interactions. Both DHFR and BCL-2 have most of the potential inhibitors interacting with hydrogen bonds and van der Waals (see Fig. 4). Generally, the specific molecular interactions between ligands and receptors are the main driver of cell-to-cell communication, and dysregulation in these interactions is implicated in diseases such as cancer, 


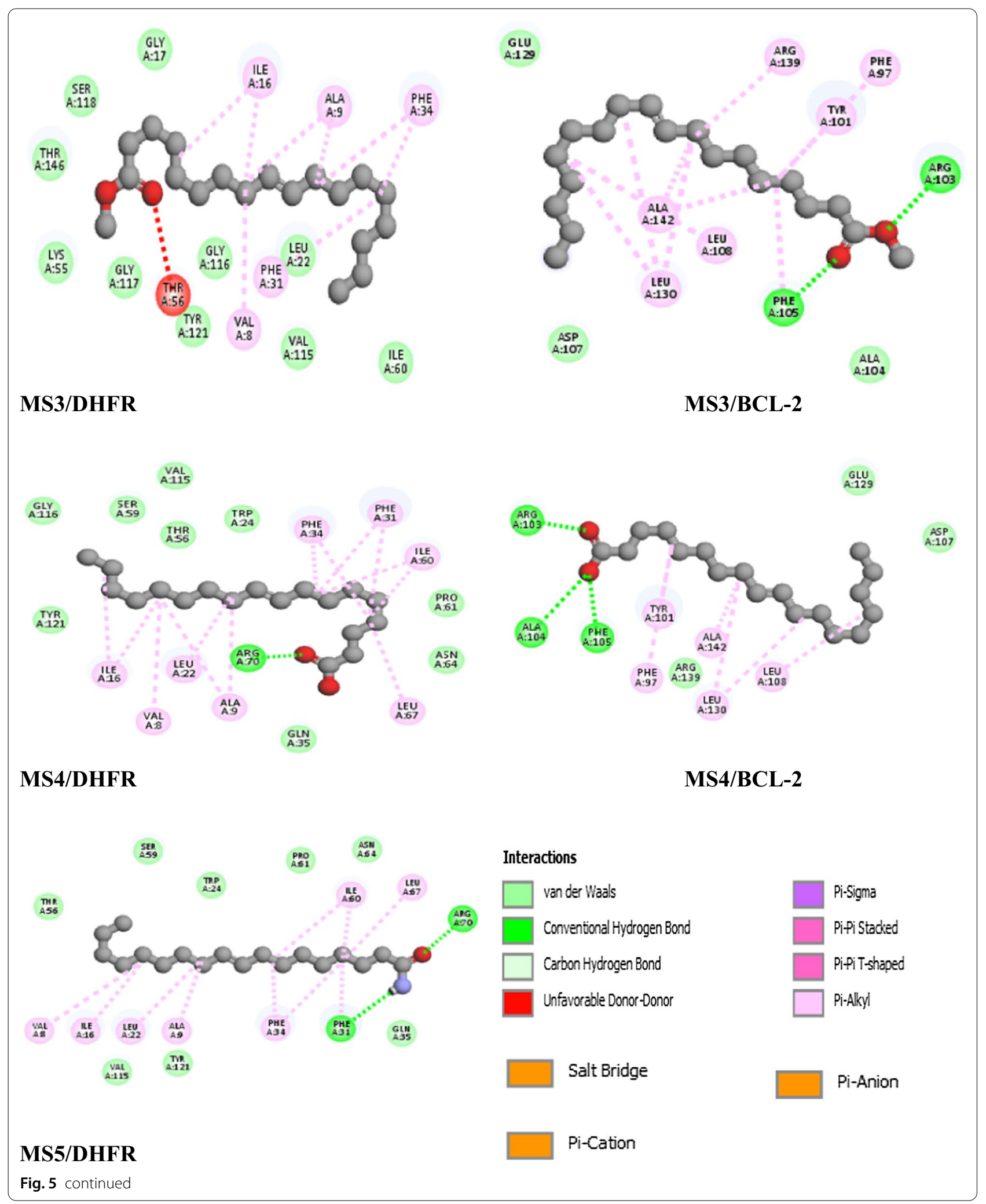


Table 2 Drug likeness of the potential inhibitors from swissadme server

\begin{tabular}{|c|c|c|c|c|c|c|c|}
\hline \multirow[t]{2}{*}{ Compound ID } & \multirow[t]{2}{*}{ Molecular weight } & \multicolumn{2}{|c|}{ Hydrogen bonds } & \multirow[t]{2}{*}{ RotatableBonds } & \multirow[t]{2}{*}{$\log P\left(\right.$ iLog $\left.P_{o / w}\right)$} & \multirow[t]{2}{*}{ TPSA } & \multirow{2}{*}{$\begin{array}{l}\text { RO5 } \\
\text { violation }\end{array}$} \\
\hline & & Donor & Acceptor & & & & \\
\hline ML2 & 128.26 & 0 & 0 & 3 & 2.79 & $0^{\mathrm{a}}$ & 1 \\
\hline ML4 & 161.24 & 1 & 0 & 3 & 2.66 & 12.36 & 0 \\
\hline ML5 & 206.32 & 1 & 1 & 2 & 2.86 & 20.23 & 0 \\
\hline ML6 & 240.42 & 1 & 1 & $14^{\mathrm{a}}$ & 4.23 & 20.23 & 1 \\
\hline ML7 & 296.53 & 1 & 1 & $13^{\mathrm{a}}$ & 4.66 & 20.23 & 1 \\
\hline ML8 & 270.45 & 2 & 0 & $15^{\mathrm{a}}$ & 4.41 & 26.3 & 1 \\
\hline ML9 & $652.94^{\mathrm{a}}$ & 8 & 2 & $34^{\mathrm{a}}$ & 7.58 & 119.36 & 2 \\
\hline ML10 & 296.53 & 1 & 1 & $13^{\mathrm{a}}$ & 4.66 & 20.23 & 1 \\
\hline ML11 & 282.46 & 2 & 1 & $15^{\mathrm{a}}$ & 4.27 & 37.3 & 1 \\
\hline ML12 & 324.54 & 2 & 0 & $12^{\mathrm{a}}$ & 4.85 & 26.3 & 1 \\
\hline ML13 & $883.42^{\mathrm{a}}$ & 6 & 0 & $51^{\mathrm{a}}$ & 11.69 & 78.9 & 2 \\
\hline ML14 & 252.44 & 1 & 0 & $13^{\mathrm{a}}$ & 4.07 & 17.07 & 1 \\
\hline ML15 & 390.56 & 4 & 0 & $18^{\mathrm{a}}$ & 4.14 & 52.6 & 1 \\
\hline MS1 & 270.45 & 2 & 0 & $15^{\mathrm{a}}$ & 4.41 & 26.3 & 1 \\
\hline MS2 & $652.94^{\mathrm{a}}$ & 8 & 2 & $34^{\mathrm{a}}$ & 7.58 & 119.36 & 2 \\
\hline MS3 & 296.49 & 2 & 0 & $16^{\mathrm{a}}$ & 4.75 & 26.3 & 1 \\
\hline MS4 & 282.46 & 2 & 1 & $15^{\mathrm{a}}$ & 4.27 & 37.3 & 1 \\
\hline MS5 & 281.48 & 1 & 1 & $15^{\mathrm{a}}$ & 4.22 & 43.09 & 1 \\
\hline
\end{tabular}

${ }^{a}$ RO5 (Lipinski rule of five) violations, TPSA topological polar surface area, Log $P$ octanol-water partition coefficient

Table 3 Pharmacokinetics properties of the potential inhibitors from swissadme server

\begin{tabular}{|c|c|c|c|c|c|c|c|c|}
\hline Compound ID & Gl absorption & BBB permeant & Pgp substrate & $\begin{array}{l}\text { CYP1A2 } \\
\text { inhibitor }\end{array}$ & $\begin{array}{l}\text { CYP2C19 } \\
\text { inhibitor }\end{array}$ & $\begin{array}{l}\text { CYP2C9 } \\
\text { inhibitor }\end{array}$ & $\begin{array}{l}\text { CYP2D6 } \\
\text { inhibitor }\end{array}$ & $\begin{array}{l}\text { CYP3A4 } \\
\text { inhibitor }\end{array}$ \\
\hline ML2 & Low & Yes & No & No & No & No & No & No \\
\hline ML4 & High & Yes & No & Yes & No & No & Yes & No \\
\hline ML5 & High & Yes & No & No & No & No & Yes & No \\
\hline ML6 & High & Yes & No & Yes & No & No & No & No \\
\hline ML7 & Low & No & Yes & No & No & Yes & No & No \\
\hline ML8 & High & Yes & No & Yes & No & No & No & No \\
\hline ML9 & Low & No & Yes & No & No & No & No & No \\
\hline ML10 & Low & No & Yes & No & No & Yes & No & No \\
\hline ML11 & High & No & No & Yes & No & Yes & No & No \\
\hline ML12 & Low & No & No & Yes & No & Yes & No & No \\
\hline ML13 & Low & No & Yes & No & No & No & No & No \\
\hline ML14 & High & No & No & Yes & No & Yes & No & No \\
\hline ML15 & High & No & No & No & No & No & No & Yes \\
\hline MS1 & High & Yes & No & Yes & No & No & No & No \\
\hline MS2 & Low & No & Yes & No & No & No & No & No \\
\hline MS3 & High & No & No & Yes & No & No & No & No \\
\hline MS4 & High & No & No & Yes & No & Yes & No & No \\
\hline MS5 & High & Yes & No & Yes & No & Yes & No & No \\
\hline
\end{tabular}

Gl gastrointestinal, BBB blood-brain barrier, Pgp P-glycoprotein, CYP Cytochrome P

autoimmunity, and neurodegeneration (Hsu and Hung 2016; Charbonnier et al. 2015; Villar-Cheda et al. 2014). The potential to specifically modulate protein-protein interactions has inspired the development of targeted therapeutics against ligands and receptors, with efforts dating back to the early twentieth century (Strebhardt 
Table 4 Toxicity of the potential inhibitors from pkCSM server

\begin{tabular}{|c|c|c|c|c|c|}
\hline Compound ID & AMES toxicity & hERG I inhibitor & hERG II inhibitor & Hepatotoxicity & $\begin{array}{l}\text { Skin } \\
\text { sensitization }\end{array}$ \\
\hline ML2 & No & No & No & No & No \\
\hline ML4 & No & No & No & Yes & Yes \\
\hline ML5 & No & No & No & No & Yes \\
\hline ML6 & No & No & No & No & Yes \\
\hline ML7 & No & No & Yes & No & Yes \\
\hline ML8 & No & No & No & No & Yes \\
\hline ML9 & No & No & No & No & No \\
\hline ML10 & No & No & Yes & No & Yes \\
\hline ML11 & No & No & No & Yes & Yes \\
\hline ML12 & No & No & No & No & Yes \\
\hline ML13 & No & No & No & No & No \\
\hline ML14 & No & No & No & No & Yes \\
\hline ML15 & No & No & Yes & No & No \\
\hline MS1 & No & No & No & No & Yes \\
\hline MS2 & No & No & No & No & No \\
\hline MS3 & No & No & No & No & Yes \\
\hline MS4 & No & No & No & Yes & Yes \\
\hline MS5 & No & No & Yes & No & Yes \\
\hline Compound ID & $\begin{array}{l}\text { MTD (Human) Log (mg/ } \\
\text { kg/day) }\end{array}$ & LD50 ( $\mathrm{mol} / \mathrm{kg})$ & $\begin{array}{l}\text { LOAEL Log (mg/ } \\
\text { kg_bw/day) }\end{array}$ & T.pT Log $(\mu \mathrm{g} / \mathrm{L})$ & MT Log (mM) \\
\hline ML2 & 0.486 & 1.573 & 2.366 & 0.597 & 0.522 \\
\hline ML4 & 0.739 & 1.967 & 1.947 & 1.131 & 0.893 \\
\hline ML5 & 0.081 & 2.118 & 2.015 & 1.690 & 0.205 \\
\hline ML6 & 0.021 & 1.534 & 1.120 & 2.065 & -0.850 \\
\hline ML7 & 0.133 & 1.603 & 1.043 & 1.903 & -1.590 \\
\hline ML8 & 1.178 & 1.635 & 2.998 & 1.935 & -1.373 \\
\hline ML9 & 0.328 & 2.754 & 3.415 & 0.285 & -6.020 \\
\hline ML10 & 0.133 & 1.603 & 1.043 & 1.903 & -1.590 \\
\hline ML11 & -0.943 & 1.604 & 3.251 & 0.366 & -1.438 \\
\hline ML12 & 0.228 & 1.725 & 2.815 & 2.120 & -1.744 \\
\hline ML13 & 0.442 & 2.552 & 0.529 & 0.285 & -13.725 \\
\hline ML14 & 0.085 & 1.503 & 1.122 & 2.010 & -1.236 \\
\hline ML15 & 1.236 & 1.332 & 2.733 & 0.676 & -3.150 \\
\hline MS1 & 0.178 & 1.635 & 2.998 & 1.935 & -1.373 \\
\hline MS2 & 0.328 & 2.754 & 3.415 & 0.285 & -6.020 \\
\hline MS3 & 0.040 & 1.637 & 3.075 & 1.529 & -1.727 \\
\hline MS4 & -0.943 & 1.604 & 3.251 & 0.366 & -1.438 \\
\hline MS5 & -0.245 & 1.773 & 0.920 & 1.637 & -1.120 \\
\hline
\end{tabular}

AMES mutagenicity, $h E R G$ human ether-a-go-go gene, MTD maximum tolerated dose, LD50 oral rat acute toxicity, LOAEL oral rat chronic toxicity, T.pT T. pyriformis Toxicity, MT minnow toxicity

and Ullrich 2008). Cell surface receptors and their cognate ligands provide unique opportunities for drug development (Gashaw et al. 2012; Smith 2015). Different approaches can be used for targeting ligands or receptors. For instance, soluble ligands or the extracellular domain of a receptor allows circulating drugs access to functional sites, particularly compared to intracellular targets which have been mostly considered 'undruggable' by biologics (Hennemann et al. 2015). Also, many ligands and receptors are involved in cell growth or survival, there is a potential for both selective targeting and functional blockade (Kim and Cochran 2017). However, epidermal growth factor receptor (EGFR) and human epidermal growth factor receptor 2 (HER2) regulate cell 
proliferation and survival, and their expression at high levels on tumors is associated with poor prognosis in many human cancers (Hsu and Hung 2016). As observed in Fig. 3 which shows that BCL-2 is a surface receptor, cell surface receptor targets have been especially important for localizing therapeutic modalities to tumors (Gashaw et al. 2012; Smith 2015). Target dynamics affect and are affected by therapeutic proteins such as DHFR and BCL-2 (Table 1). There is a need to understand the distribution and regulation of the disease target as this will help to determine the specificity and efficacy of the directed therapy. An instance is that a more prominent expression of the target in certain physiological locations or disease states can provide organ or tissue selectivity (Hussain et al. 2014). However, most molecular targets are not exclusively expressed by a single cell or tissue type (Uhlen et al. 2015). The ability of a therapeutic to internalize following receptor binding can also be utilized for targeted drug delivery too (see Fig. 3). However, a net decrease in the number of cell surface receptors induced by the therapeutic agent can affect targeting efficiency for subsequent dosing (Kim and Cochran 2017). In addition to internalization, most receptor proteins shed their extracellular domains to some degree, resulting in both membrane-bound and soluble forms of a target ( $\mathrm{Li}$ et al. 2014; Miller et al. 2016).) The coexistence of the shed receptor can act as a sink and thus influence the binding of a protein drug to its pharmacological cell surface receptor target (Kim and Cochran 2017). For a better understanding of the pharmacological and pharmacokinetic properties of these potential inhibitors extracted from M. oleifera, ADMET profile was also predicted.

Lipinski rule of five (RO5) is an indicator of drug-likeness of small molecules. In the overall assessment, ML4 and ML5 obeyed all the RO5. ML2, ML6, ML7, ML8, ML10, ML11, ML12, ML14, ML15, MS1, MS3, MS4, and MS5 violate one RO5, whereas ML9, ML13, and MS2 violated two of the RO5 (see Table3). Swissadme server was used to study the drug-likeness by considering the physicochemical properties in terms of Lipinski RO5. Nisha et al. (2016) stated that lower molecular weights enhance the absorption rate and the iLog $P$ value (logarithm of noctanol-water partition coefficient of a compound) is a fixed measure of a compound's lipophilicity. Higher iLog $P$ value indicates lower lipophilicity and, thus, poor absorption and permeation. Hydrogen bonds help in determining the specificity of ligand binding. TPSA (Topological Polar Surface Area) indicates the surface belonging to polar atoms in the compound. An increased TPSA is associated with diminished membrane permeability and compounds with higher TPSA are better substrates for p-glycoprotein (responsible for drug efflux from a cell) (Blake 2000). Thus comparing the potential inhibitors, lower TPSA was favorable for a drug-like property. It has also been predicted that a molecule with better BBB permeation should have a lower TPSA value (Chico et al. 2009). In the light of these, ML4 and ML5 showed a better likelihood of therapeutic success of all the potential inhibitors since they do not violate any of the Lipinski RO5.

Pharmacokinetic properties are another indicator of the likelihood of therapeutic success for drug molecules like these potential inhibitors. High GI absorption denotes that the compound could be better absorbed from the intestinal tract upon oral administration. Compounds with low GI absorption could be administered through other routes rather than oral administration. ML4, ML5, ML6, ML8, ML11, ML14, ML15, MS1, MS3, MS4, and MS5 all exhibit high GI absorption (Table 4). ML2, ML4, ML5, ML6, ML8, MS1, and MS5 are blood-brain barrier (BBB) permeants that show they can attain bioavailability in the neurological pathways, thus, therapeutic potentials for neuro-degeneration. In predicting the efflux by $p$-glycoprotein, ML7, ML9, ML10, ML13, and MS2 came out as the substrates. CYP450 is the machinery for drug metabolism. Non-inhibitors of CYP450 isoforms (CYP1A2, CYP2C19, CYP2C9, CYP2D6, and CYP3A4) do not interfere with the biotransformation of drugs metabolized by the CYP450 enzyme. Only ML2, ML4, ML9, ML13, and MS2 are non-inhibitors whereas others are inhibitors of at least one of all the CYP450 isoforms (see Table 3).

The suitability of small molecules to be chosen as a lead compound in drug discovery depends on their levels of toxicity (Nisha et al. 2016). Table 4 shows the outcome predicting the toxicity of the potential inhibitors. AMES test predicts if a compound is mutagenic, hence carcinogenic. Virtually, all the potential inhibitors are non-carcinogenic. The human ether-a-go-go related gene (hERG) potassium channel is an anti-drug implicated in cardiac repolarization linked to arrhythmia. The hERG inhibitory drugs are being withdrawn from the market due to their toxic effect. ML7, ML10, ML15, and MS5 are hERG II inhibitors whereas none of the inhibitors are hERG I inhibitors. Also, ML4, ML11, and MS4 are hepatotoxic, hence their ingestion could alter the normal hepatic states. Except for ML2, ML9, ML13, ML15, and MS2 others can sensitize the skin. Skin sensitization is toxic and can trigger allergic contact dermatitis (Nisha et al. 2016).

MTD gives an estimate of the toxic dose threshold of chemicals in humans, hence, an insight on starting dose for pharmaceuticals in phase I clinical trials (Nisha et al. 2016). MTD $\leq 0.477$ is considered low and MTD $>0.477$ is considered high. In their order of increasing value ML2, $>$ ML4 > ML8 > ML15 have high whereas others have low MTD. Important information obtained from the pkCSM 
server was the measure of acute toxicity (LD50) dose in a rat model. In comparing the LD50 doses, a compound with a lower dose is more lethal than the compound having a higher LD50. Observations from our study showed that ML5, ML13, and MS2 are comparatively less lethal than other potential inhibitors. Estimation of chronic toxicity is also important to determine the highest dose of which no adverse effects are observed. That is the oral rat chronic toxicity (LOAEL) of the potential inhibitors. However, LOAEL for a compound depends on the bioactive concentration and length of treatment required. T. pyriformis toxicity and Minnow toxicity are regarded as toxic endpoints (IGC50) and lethal concentration values (LC50) respectively. Thus, IGC50 > $-0.5 \log \mu \mathrm{g} / \mathrm{L}$ is considered toxic and LC50 values below $0.5 \mathrm{mM}$ $(\operatorname{logLC} 50<-0.3)$ are regarded as high acute toxicity (see Table 4).

\section{Conclusion}

The growing incidence of cancer and various limitations in conventional therapy including the high cost and high toxicity of present anticancer drugs posed a challenge to design and develop an alternative with less or no limitations. It was evident from our present study that $M$. oleifera leaves and seeds can be a source of a greener way for intervening in the cancer upsurge. Gas chromatographyMass Spectrometer compounds from $M$. oleifera leaves and seeds extract showed affinities for DHFR and BCL-2 known to be the disease protein in cancer proliferation thereby inhibiting them. Through the ADMET profile, in this study, we have unveiled an insight into the success of these potential inhibitors as candidates in drug discovery and this will be a step to pharmaceuticals in their phase 1 clinical trial. Also, this study has revealed a novel economic value of $M$. oleifera, thus, new cancer therapeutics can be designed to replace the existing ones which have numerous limitations.

\begin{abstract}
Abbreviations
ADMET: Absorption, distribution, metabolism, excretion, toxicity; BAX/BAK: Nuclear-encoded proteins present in higher eukaryotes that pierce the mitochondrial outer membrane to mediate apoptosis.; $\mathrm{BH} 3 / \mathrm{BH} 2$ mimetic: Homology domains of BCL-2 family; CID: Compound Identification Number; MCL1, BCLXL, BCLW, NOXA, BCL-1, BCL-2A1: Subfamily of BCL-2; PDB: Protein Data Bank; pkCSM: An online server for predicting ADMET property of a compound; RCSB: Research Collaboratory for Structural Bioinformatics; RMSD: Root-mean-square deviation.
\end{abstract}

\section{Acknowledgements}

This work received administrative support from the Faculty of Science Academic board, Ebonyi State University, Abakaliki, Nigeria.

\section{Authors' contributions}

In this study, all the authors have made useful contributions. Conceptualization, APC and APM; methodology, APC, and DT; software, AJN, OHA, and EEU; validation, $A A E$, and APM; analysis, DT and EEU; investigation, APC, APM, and EEM; data curation, EEM, and OHA; writing —original draft preparation, APM,
APC, and IAU; writing - review and editing, APM, UEl, and AJN; visualization, $\mathrm{EEM}, \mathrm{AAE}$, and APC; supervision, IIO, AEU, and UEl; project administration, IAU and ACA. All authors read and approved the final manuscript.

Funding

The authors did not receive any funding to carry out the study.

\section{Availability of data and materials}

The software used were ACD/ChemSketch to synthesize the test compounds (see Table 2); UCSF Chimera to generated 3D structure of target proteins, test compounds, and standard inhibitors (see Figs. 1, 3, and 4); AutoDock Vina plugin PyRx for virtual screening to predict binding affinities and MS-Excel to plot the bar chart (see Fig. 2); Studio 2020 to visualize the protein-ligand interactions (see Fig. 5). Web servers used were Fig. 1: Protein Data Bank server (www.rcsb.pdb.com) to retrieve target protein, and PubChem database to retrieve the standard inhibitors; Tables 3: SwissAdme web server (http://www. swissadme.ch/) to check for Lipski rule of five (RO5) violations and pharmacokinetics properties of potential inhibitors; Table 4: pkCSM web server (http:// biosig.unimelb.edu.au/pkcsm/prediction) to predict toxicities of the potential inhibitors.

\section{Declarations}

Ethical approval and consent to participate

Not applicable.

Consent for publication

Not applicable.

\section{Competing interests}

The authors do not declare any conflict of interest about this research.

\section{Author details}

${ }^{1}$ Department of Biochemistry, Faculty of Science, Ebonyi State University, P. M.B 053, Abakaliki, Nigeria. ${ }^{2}$ Department of Chemical Engineering, Caritas University, Amorji-Nike, Enugu State, Nigeria. ${ }^{3}$ Department of Biochemistry, Faculty of Medical Sciences, University of Jos, Jos, Nigeria. ${ }^{4}$ Jaris Computational Biology Center, Jos, Nigeria. ${ }^{5}$ Department of Science Laboratory Technology, Oko Federal Polytechnics, Oko, Anambra State, Nigeria. ${ }^{6}$ Department of Biochemistry, Mbarara University of Science and Technology (MUST), Mbarara, Uganda. ${ }^{7}$ Department of Biotechnology, Faculty of Science, Ebonyi State University, P. M.B 053, Abakaliki, Nigeria.

Received: 6 April 2021 Accepted: 11 May 2021

Published online: 26 May 2021

\section{References}

Aja PM, Nwachukwu N, IbiamlgwenyiOfforOrji AUIOCEUO (2014) Chemical constituents of Moringa oleifera leaves and seeds from Abakaliki, Nigeria. Am J Phytomed Clin Ther 2(3):310-321

American Cancer Society (2016) Cancer facts and figures 2016. American Cancer Society, Atlanta

Anderson MA, Deng J, Seymour JF et al (2016) The BCL2 selective inhibitor venetoclax induces rapid onset apoptosis of CLL cells in patients via a TP53-independent mechanism. Blood 127(25):3215-3224

Ashraf MA (2020) Phytochemicals as potential anticancer drugs: time to Ponder Nature's Bounty. Biomed Res Int 8602879:7. https://doi.org/10. 1155/2020/8602879

Aung TN, Qu Z, Kortschak RD, Adelson DL (2017) Understanding the effectiveness of natural compound mixtures in cancer through their molecular mode of action. Int J Mol Sci 18(3):656

Blake JF (2000) Chemoinformatics-predicting the physicochemical properties of "drug-like" molecules. Curr Opin Biotechnol 11(1):104-107

Burchenal JH, Goetchius SK, Stock CC, Hitchings GH (1952) Diamino dichlorophenyl pyrimidines in mouse leukemia. Can Res 12:251

Caruso M, Colombo AL, Fedeli L, Pavesi A, Quaroni S, Saracchi M et al (2000) Isolation of endophytic fungi and actinomycetes taxane producers. Ann Microbiol 50:3-14 
Charbonnier LM, Janssen E, Chou J, Ohsumi TK, Keles S, Hsu JT, Massaad MJ, Garcia-Lloret M, Hanna-Wakim R, Dbaibo G et al (2015) Regulatory T-cell deficiency and immune dysregulation, polyendocrinopathy, enteropathy, X-linked-like disorder caused by loss-of-function mutations in LRBA. J Allergy Clin Immunol 135:U217-U336

Chen L, Willis SN, Wei A et al (2005) Differential targeting of prosurvival BCl-2 proteins by their $\mathrm{BH} 3$-only ligands allows complementary apoptotic function. Mol Cell 17(3):393-403

Chico LK, Van Eldik LJ, Watterson DM (2009) Targeting protein kinases in central nervous system disorders. Nat Rev Drug Discov 8(11):892-909

Cory S, Adams JM (2002) The Bcl2 family: regulators of the cellular life-or-death switch. Natl Rev Cancer 2(9):647-656

Fischer GA (1961) Increased levels of folic acid reductase as a mechanism of resistance to amethoptcrin in leukemic cells. Biochem Pharmacol 7:75-77

Gashaw I, Ellinghaus P, Sommer A, Asadullah K (2012) What makes a good drug target? Drug Discov Today 17:S24-S30

Guièze R, Liu VM, Rosebrock D et al (2019) Mitochondrial reprogramming underlies resistance to $B C L-2$ inhibition in lymphoid malignancies. Cancer Cell 36(4):369-384.e13

Hamrell MR (1984) Inhibition of dihydrofolate reductase and cell growth by antifolates in a methotrexate-resistant cell line. Oncology 41:343-348

Hennemann H, Wirths S, Carl C (2015) Cell-based peptide screening to access the undruggable target space. Eur J Med Chem 94:489-496

Hill BT, Goldie JH, Price LA (1973) Studies concerned with overcoming resistance to methotrexate: a comparison of the effects of methotrexate and 2.4-diamino-5-(3'.4'-dichloro- phenyl)-6-mcthylpyrimidine (BW50197) on the colony-forming ability of L5I78Y cells. Br J Cancer 28:263-268

Ho YK, Hakala MT, Zakrzewski SF (1972) 5-(I-Adamantyl)- pyrimidines as inhibitors of folate metabolism. Can Res 32:1023-1028

Hsu JL, Hung MC (2016) The role of HER2, EGFR, and other receptor tyrosine kinases in breast cancer. Cancer Metastasis Rev 35:575-588

Hussain S, Rodriguez-Fernandez M, Braun GB, Doyle FJ, Ruoslahti E (2014) Quantity and accessibility for specific targeting of receptors in tumors. Sci Reprod 4:5232

Iqbal J, Abbasi AA, Mahmood T, Kanwal S, Ali B, Shah AS, Khalil AT (2017) Plantderived anticancer agents: a green anticancer approach. Asian Pac J Trop Biomed 7(12):1129-1150

Jones CL, Stevens BM, D'Alessandro A et al (2018) Inhibition of amino acid metabolism selectively targets human leukemia stem cells. Cancer Cell 34(5):724-740.e4

Kim JW, Cochran JR (2017) Targeting ligand-receptor interactions for the development of cancer therapeutics. Curr Opin Chem Biol 38:62-69

Krishnamurthi K (2007) 17-screening of natural products for anticancer and anti-diabetic properties. Cancer 3:4

Lagadinou ED, Sach A, Callahan K et al (2013) BCL-2 inhibition targets oxidative phosphorylation and selectively eradicates quiescent human leukemia stem cells. Cell Stem Cell 12(3):329-341

Lessene G, Czabotar PE, Colman PM (2008) BCL-2 family antagonists for cancer therapy. Natl Rev Drug Discov 7(12):989-1000

Letai AG (2008) Diagnosing and exploiting cancer's addiction to blocks in apoptosis. Natl Rev Cancer 8(2):121-132

Li L, Gardner I, Rose R, Jamei M (2014) Incorporating target shedding into a minimal PBPK-TMDD model for monoclonal antibodies. CPT Pharmacomet Syst Pharmacol 3:e96

McArthur K, Whitehead LW, Heddleston JM et al (2018) BAK/BAX macropores facilitate mitochondrial herniation and mtDNA efflux during apoptosis. Science 359(6378):eaao6047

Miller MA, Oudin MJ, Sullivan RJ, Wang SJ, Meyer AS, Im H, Frederick DT, Tadros J, Griffith LG, Lee H et al (2016) Reduced proteolytic shedding of receptor tyrosine kinases is a post-translational mechanism of kinase inhibitor resistance. Cancer Discov 6:382-399

Mishra LC, Rosen F, Nichol CA (1973) Studies designed to overcome the resistance of Walker carcinoma 256 to amethoptcrin. Proc Am Assess Cancer Res 8:47

Nichol CA (1968) Studies of dihydrofolate reductase related to the drug sensitivity of microbial and neoplastic cells. Adv Enzyme Regul 6:305-322

Nichol CA, Cavalitlo JC, Wooley JL, Sigcl CW (1977) Lipid soluble diamino pyrimidine inhibitors of dihydrofolate reductase. Cancer Treat Repair 61(559):564

Nisha CM, Kumar A, Nair P, Gupta N, Silakari C, Tripathi T, Kumar A (2016) Molecular docking and in silico ADMET study reveals acylguanidine 7a as a potential inhibitor of $\beta$-secretase. Adv Bioinform 9258578:6. https://doi. org/10.1155/2016/9258578

Roberts AW (2020) Inhibiting BCL-2 with venetoclax. The American Society of Hematology. https://doi.org/10.1182/hematology.2020000154

Roberts AW, Huang D (2017) Targeting BCL2 with BH3 mimetics: basic science and clinical application of venetoclax in chronic lymphocytic leukemia and related B cell malignancies. Clin Pharmacol Ther 101(1):89-98

Roberts AW, Davids MS, Pagel JM et al (2016) Targeting BCL2 with venetoclax in relapsed chronic lymphocytic leukemia. N Engl J Med 374(4):311-322

Siegel RL, Miller KD, Jemal A (2016) Cancer statistics, 2016. CA Cancer J Clin 66(1):7-30

Siegel RL, Miller KD, Fedewa SA, Ahnen DJ, Meester RG, Barzi A et al (2017) Colorectal cancer statistics. CA Cancer J Clin 67(3):177-193

Smith AJ (2015) New horizons in therapeutic antibody discovery: opportunities and challenges versus small-molecule therapeutics. J Biomol Screen 20:437-453

Souers AJ, Leverson JD, Boghaert ER et al (2013) ABT-199, a potent and selective $B C L-2$ inhibitor, achieves antitumor activity while sparing platelets. Natl Med 19(2):202-208

Strebhardt K, Ullrich A (2008) Paul Ehrlich's magic bullet concept: 100 years of progress. Natl Rev Cancer 8:473-480

Tariq A, Sadia S, Pan K, Ullah I, Mussarat S, Sun F et al (2017) A systematic review on ethnomedicines of anti-cancer plants. Phytother Res 31:202-264

Thakore P, Mani RK, Kavitha SJ (2012) A brief review of plants having anticancer properties. Int J Pharm Res Dev 3:129-136

Tsujimoto Y, Cossman J, Jaffe E, Croce CM (1985) Involvement of the BCL-2 gene in human follicular lymphoma. Science 228(4706):1440-1443

Uhlen M, Fagerberg L, Hallstrom BM, Lindskog C, Oksvold P, Mardinoglu A, Sivertsson A, Kampf C, Sjostedt E, Asplund A et al (2015) Proteomics. Tissue-based map of the human proteome. Science 347:1260419

Villar-Cheda B, Dominguez-Meijide A, Valenzuela R, Granado N, Moratalla R, Labandeira-Garcia JL (2014) Aging-related dysregulation of dopamine and angiotensin receptor interaction. Neurobiol Aging 35:1726-1738

Vinogradov S, Wei X (2012) Cancer stem cells and drug resistance: the potential of nanomedicine. Nanomedicine 7:597-615

Vogler M, Dinsdale D, Dyer MJS, Cohen GM (2013) ABT-199 selectively inhibits $B C L 2$ but not BCL2L1 and efficiently induces apoptosis of chronic lymphocytic leukemic cells but not platelets. Br J Haematol 163(1):139-142

Weaver BA (2014) How taxol/paclitaxel kills cancer cells. Mol Biol Cell 25(18):2677-2681

\section{Publisher's Note}

Springer Nature remains neutral with regard to jurisdictional claims in published maps and institutional affiliations. 